\title{
Practices of Social Justice in the Experiences of Private School Teachers
}

\author{
Dawa Sherpa \\ dawa084@gmail.com \\ Lecturer \\ Central Department of Education, T.U., Kirtipur
}

\begin{abstract}
Private schools have become the choice for the quality of education for both parents and students. Private school associations can influence government officials and policy regarding on the contribution on education system of country. However, the voices of the private school's teachers are not amplified in the lines of decision making process. In this context, this study aims to explore the present social justice practices in the experience of private school teacher. For this purpose, narrative inquiry design has been adopted. Purposively, four participants from different private schools in the Kathmandu valley are selected. An in-depth interview with teachers was conducted to assess the teachers' perspectives on social justice. To isolate the primary subject, the transcribed data was coded and reorganized by decoding. Data triangulation was employed to assure the accuracy of our study and results. Study found, the school's leadership cannot ensure justice on its own. Inclusion of a diverse range of people is inadequately handled. The teaching and non-teaching staffs have lack of understanding and trust in one another. School leadership does not appreciate and respect their needs, desires, or interests. Teachers are less priorities and they do not involve in planning and decision-making process of school.
\end{abstract}

Keywords : Private school, leadership, social justice, transparency and fairness, Interpersonal relationship

\section{Introduction}

Private schools have become the choice of most parents in Nepal to teach their children. The private school has challenged the community school in providing quality education (Carney \& Bista, 2009). So, all the businessmen, politicians, and government service holders, including teachers, are choosing private schools. However, most private school teachers are choosing to work at community schools (Mathema, 2007). Businessmen are investing their capital in education. They have invested more in private schools and colleges. Private school fees are prohibitively expensive (Koirala, 2015)for middle-class families who rely solely on their basic salary. To conduct a private school, they need authority and acceptance from the government. They have their own association (Private School Associations) for their rights and welfare. They can put great pressure on the government. If they wish, they are able to change government 
educational policy. Private school owners have supported political leaders economically in large amounts (Mathema, 2007). In this revenge, they want to shift the policy as they wish. Nevertheless, teachers remain in the shadows. The voices of private school teachers are not amplified.

Teachers are the main agents for providing education. The student's achievement is determined by the teacher's overall performance. So teachers need to contribute more time to students (Aslam, 2009). Teaching in a classroom and completing a course doesn't matter. However, a student's good score on the final exam is important. The student's weaknesses and misconduct are considered the teacher's weaknesses that he can treat and counsel well enough. Teachers are monitored and observed by various levels of management as well as parents and society in limited pay(Mathema, 2007). In this sense, teachers need to be sincere, competent, and responsible in school and out of school.

Regarding the roles and responsibilities of teachers from the standpoint of social justice, how do teachers enjoy their time in the institution with students, staff, and school leadership? How they interact in terms of their rights. How do they get paid and what kind of benefits do they get? What is their position and standing at school? How they were promoted, as well as their role in planning and decision-making are the key issues for this study. This study brought up problems such as a teacher's concealed pain and pleasure, what is just and unjust, and dominance and empowerment.

\section{Objectives}

The objective of the study is to explore the social justice practices in private or institutions school.

\section{Review of Social Justice Leadership}

Social justice is an umbrella term with multiple meanings. It covers a range of terms some are more powerful than others such as equity, equality, inequality, equal opportunity, affirmative action, and most recently respect for diversity(Furman, 2012). Social justice has three major identifying aspects distributive, cultural, and associational. Distributive justice refers to the Rawlsian concern with the equitable distribution of goods in society, cultural justice means the absence of both cultural domination and "non-recognition" of cultural groups, and associational justice refers to the full participation of marginalized groups in decisions (Gewirtz \& Cribb, 2002). Social justice overviews beliefs about what is right, good, desirable, and moral. Concept of social justice concerns the equal worth of all citizens, their equal right to meet their basic needs, the need to spread opportunity and life chances as widely as possible, fairness in the fundamental rights and duties, economic opportunities and social conditions(Jean-Marie, 2008).

Social justice leadership is fair and equitable cultures and practices in terms of ensuring social justice in society or certain organizations. It has also been characterized as rebellious and varying institutionalized inequities, discrimination, and injustices that benefit few students and harm many more (Turhan, 2010). Social justice doesn't include only fair treatment, involvement and empowerment it focuses on democratic participation in decision making, transformation 
of inequitable social arrangements, inclusive practices in response to diversity, and critical awareness in leadership practice, respectively (Wang, 2018). Achievements and economic well-being of minorities, back warded and marginalized groups that focus on creating equal opportunities concern the social justice leadership (Furman \& Gruenewald, 2004).

Social justice leadership is a change factor in the organization and society and nations. All human beings are equal in terms of the nature of their birth. Nature treats them equally but growing civilization brought variations and made different based on caste and ethnicity, religions. Now human beings have many diversities. Respect for diversities and humanity is main issues for the successful leaders. Social justice leadership is to provide fair and equitable justice to all the students and teacher staff. It creates them proud, safe, and secure (Goldfarb \& Grinberg, 2002). Social justice leadership is about ensuring that all individuals and cultural groups have access to social capital that includes educational opportunity for academic success. They posit that all leaders must take on this encounter if they are to enable future leaders to work toward the mission of bonding all people. Such engagement can, importantly, have the effect of educating tomorrow's leaders and transforming perspectives about critical social justice issues. Social justice capacities that school leaders can transfer to their domains include being able to both recognize and successfully negotiate dynamics of race, gender, and class in relationships (Mullen, 2008).

Social justice leadership in education is possible by maintaining the opportunity for all the students and teachers. Fair treatment, natural justice and rule of law are the prime rule for social justice. Leaders need to present him as a member of the team. According to (Rawls, 1999) the basic right and liberty, right to vote and hold public offices, freedom of speech and assembly, liberty of conscience, freedom of thought, freedom of person, right to hold personal property and freedom from arbitrary arrest and seizure, rule of law comes under the first principle and distribution of income and wealth design of organization that make use of different authority and responsibility and responsibility, economic and social benefit comes under the second principle. Further he states that social justice is the first virtue of social institution and justice denies that the loss of freedom. Equality and difference principles are needed to apply to maintain social justice. People need to be treated equally if they are equal in terms of diversities and if they are from diversified backgrounds, they need to be treated applying difference principle.

Social justice in education encompasses the positive discrimination of all students where diverse interest of all students are welcomed in their natural setting. The feelings and experiences of all learners are treated on the basis of their fundamental rights through the common placement. Social justice tends to discourage intensity of social, cultural, and economic inequalities imposed by composition of society. Social justice breaks down the injustice emerged with unequal distributions power, resources and privilege (Goldfarb \& Grinberg, 2002).

Maintaining social justice is challenging due to diverse ideology and understanding. Individual love to practice their own culture and belief system and love to preserve them. Individual's stereotype and fixed mind set becomes the barriers in maintain justice (Riehl, 2000). In this context individuals need to change their belief system and mind set what they have practiced in their culture? 
The attitudinal barrier refers to the stigmatization towards the creation of social justice in the society. The negative attitude, thoughts and feelings disturb the social harmony needed for the equitable society. An individual thought is completely guided by the self-centred activity and egocentric. S/he doesn't like to come out from the self-reservation and individualism for running ahead. S/he keeps competitive thought and ideology in treating with other person (Messick, 2006).

\section{Methods}

To carry out this research, I used a qualitative approach in conjunction with a constructivist paradigm. In terms of philosophical perspective, the notion of natural justice and fairness is the ontological foundation of experience regarding instructors. For this study, the narrative inquiry (Wells, 2011)was used, and purposively four teachers from the institution's school were chosen.

In the narrative study, I have opted to end my research effort by providing an in-depth account of the teacher's experience. The narrative inquiry allowed the researcher to gather information regarding the semester system's implementation (Case \& Light, 2011). Personal reflection from higher education practice was employed in the research. For the rigorous information, an in-depth interview was conducted with participant instructors. The interview response was recorded and transcribed verbatim. The transcribed material was coded and rearranged by decoding to extract the core subject(Saldana, 2021). The main subject was examined to determine the teacher's view of regarding social justice. To ensure the accuracy of our research and conclusions, we used data triangulation methods, matching our research findings with similar research and story studies conducted by other researchers.

\section{Result and Discussions}

This section contains the results of the thorough analysis of the transcribed data of the participant's interview with the support of relevant theory, as supported by the literature study. The topics and sub-themes for this study were extracted from the data, and a conclusion was reached as a result.

\section{Transparency and Fairness}

The natural justice focuses on ensuring the decision making process transparent, impartial, evidence base. It concern with procedural fairness, deep, critical, and honest self-reflection for social justice work. Similarly individual natural justice focus on self-engagement and activeness. Competitiveness, need for control, and self-esteem concerns are the necessary for self-reflections and awareness(Furman, 2012). In relation to this I make quires to teacher (P1) who have been teaching in the institutional school stated as:

I came to know the news there is vacant post for teaching maths. I met with principal sir. He asked my qualification and teaching experiences. I told I have completed bachelor form science faculty and now studying MA with major maths. Again he asked me can you teach for class 9 and 10? Yes I said. Immediately he told me come from tomorrow. Tomorrow I met principal but he told me currently school managed teacher so please contact next time. Sadly I returned home and joined next school after a week. 
This statement demonstrates that the school exhibited irresponsible and unaccountable behaviour for the candidate who was seeking for the job placement. In the leadership strategy the head teacher is showing immature and oppressed behaviour for candidate. In general sense school environment is the platform for the conservation of the democracy, instead the leadership behaviour couldn't ensure fairness with in school(Hobbs, 2010). Moreover I asked him could you find any reason for being returned. After someday, I notices the cause of returning back from the informal clues. One of the school owner decided himself to recruit less qualified teacher with low salary by the recommendation of someone else. Similarly, in the context of job placement for teaching another participant P2 told that his uncle was principal. After completed his 12 class, he was called for teaching in school.

This statement emphasized the lack of fairness and transparency in the teacher selection process. Teachers are chosen at the discretion of the institution. There aren't any exceptions. Because they are a private organization, they may hire anyone if the instructor is skilled and competent to give the lesson and please the students, and there is no disagreement from the administration (Wheelen, Hunger, Hoffman, \& Bamford, 2017). It seems that the institutions has threat the issues of social justice specially fairness and natural justice.

\section{Interpersonal Relationship with in School}

Interpersonal relationship refers to the mutual relationship among the teaching and non-teaching staffs. Internal personal relationship itself acts as fairness and embodied with deep relationship without any types of parity. Interpersonal relationship emerged as a higher order concept of transformational leadership. The transformational relationship encourage, inspire and motivate teachers and students in their work place. Interpersonal relationship has been found as effective toward work engagement(Hansen, Byrne, \& Kiersch, 2014). Students in the school are from diverse cultural backgrounds. In relation to interpersonal relationship participant teacher P3 asserted as:

Teacher staffs are collaborative helpful and more co-operative in the school. In the break time the teachers meet each other and hold informal discussion about pedagogy, teaching materials the social clues for addressing diverse need of learners. Beside this will be talking about the extent to which the students are interacting.

The premises shows that the teachers intends to discuss about the teaching content and supports to the junior staff for their carrier path. The senior teachers make junior introducing diversities management techniques inside the classroom. From this fact it is clear that the junior teachers get the opportunity to promote their professionalism. However another participant P4 asserted as:

The teacher staff meet each other for 25 to 30 minutes in break time. Most of the time we all teachers need to engage with students for sharing ideas, counsel and check their homework. So, we have not enough time to engage and discuss about the subject matter. However I know all my students to whom I teach. 
The above assertion revealed that the personal relationship and trustworthy environment is poor among teacher staff due to less involvement in academic discourse. They are always bounded by the time constraint. Less involvement among staff create the poor understanding and relationship among each other. Definitely, justice takes full engagement and interaction with the teaching and nonteaching staff without any types of discrimination(Stotzer, 2014). Similarly I asked how do principal and vice principal behave with teaching staff? In his answer he stated as:

Our principal is always busy in counselling with students and their parents. If we have problem we hardly met him. He is more responsible for students and parents rather than staffs. We discuss each other in staff meeting that is focuses on teaching learning activities and learning achievement of students.

Regarding this issue another participant teacher T4 sated as:

I had my exam for master so I requested for leave but administration didn't provide me. So I left my exam. Still I haven't completed my masters due to engage in this school. After completing this session I will left this school and complete my study.

Those statement shows that principal hasn't emphasize in sharing and caring with staff. In this scenario teachers are considered as machine. Their need, desire and interests are not valued and respected by principal. In this context interpersonal relationship with staff and administration is poor. From the perspective of interpersonal dimensions of school leadership respect, caring, active listening, and effective communication among staff develop interpersonal relationship and create positive attitude and perception towards institutions.

\section{Inclusive Leadership Practices in Education}

Inclusive leadership practice is about ensuring access to quality education for all students by effectively meeting their diverse needs in a way that is responsive, accepting, respectful and supportive. Leaders need to build inclusive communities where diverse groups are enjoying and benefiting with self-honoured (Turhan, 2010). For this sincere knowledge of communities' people, understanding of democratic and inclusive practice were required (Shah, 2018). In this context participant teacher P4 stated as:

In the school teachers are from diverse back ground in term of cast, gender, religion, geography, educational background in teaching and administration. However in leadership there is not inclusion of diverse background. Vice principal and administrative and other department head were from same family group.

This statement stated that in leadership there are only owner's and executive body's relatives concern and create trustworthy individuals in the administrative level. They dam care to teaching and nonteaching staffs. They don't like to involve in planning and decision making level to teachers. Similarly another participant P3 agreed in his statement and asserted that in the seven years gap I have taught 5 private school where school leaders were found only family related individuals in school. They were either owner or their relatives. In relation to inclusion and 
involvement of teachers in decision making process, collaboration and coordination participant P4 stated as:

Head of the department and senior subject teachers involved in planning and decision making process. Senior teachers doesn't like to collaborate and communicate with junior teachers. Poor communication among staff.

The statement revealed that the inclusive participation in decision making and involvement in other activities is not well practiced. Regarding inclusion of staff in quality instructional programs and creating opportunity for diverse voices through democratic process and decision making is important (Furman, 2012).

Cultural diversity plays an important role in an individual's life. Effective learning depends on the learners motivations. Motivation and learning differ in all individuals. It is depends on the learner's age, sex, cast and ethnicity, religious, culture (Minow, 1990). Social and cultural diversity makes motivation and learning different. People's interest depends on socio cultural environment. People like to learn their own culture language and religion but other doesn't interest. Students learn about their own and other's languages, cultural characteristics, critical events, significant individuals, historical backgrounds, majority and minority ethnic groups (Salgur \& Gursoy, 2015).

Similarly in context of inclusive education practices I asked the inclusion of students in curricular and co-curricular activities. In this context participant P3 stated as:

In classroom first and high score obtained students in class were always get emphasize in learning and they were highlighted more than other average students. They were in priority for co- curricular and extracurricular activities. Average and low scorer are always back.

This statement shows that the teachers and administration are not serious towards low score students. This reason make first scorer students always first in various activities.In the same context another participant P4 disagree and s/he asserted as:

In my school all the students are treated equally. For poor learners there were provision of extra class but they need to pay extra fees. Students are selected in different activities from diverse group. All the teachers were equally dedicated and responsible to create healthy and fare atmosphere to all students.

According to this statement all the students were treated fairly for the promotion and enlargement of their all-round development. Furthermore he told as: 
Poor students were counsel individually and supported by teacher because all teachers were dedicated for students good score in final exam. Teachers were evaluated based on the student's achievement.

The assertions show that pupils are highly prioritized, and their teaching learning for a good score is the primary goal. Students are treated and cared for on an individual basis. From the perspective of the students, it appears to be a welcoming environment with fair treatment. It is a wonderful technique to encourage and develop pupils' overall growth. On the other side, the school is increasing fees under multiple titles, making it difficult for parents to manage the school's costs.

\section{Conclusion}

In general, the school environment provides a platform for the preservation of democracy, regardless, leadership behaviour cannot assure justice inside the school. It appears that in private institutions are endangering concerns of social justice, particularly fairness and natural justice. Most of the teaching staffs have inadequate cognition about justice and fairness creating within school. Social justice lenses embraces the indicator of inclusion which is shadowed in private school. The diversity features of stakeholder need to ensure to have the better practice in social justice. Being the school as miniature of society, paradigm of social transformation need to be germinated from the school culture and practice of stakeholders. Diverse range of characteristic need to be furnished by adopting inclusive philosophy. In private school teachers were dedicated responsible and laborious for the students' achievement. The teacher's contribution need to respect and reward for their justice. School does not appreciate and respect their needs, desires, and interests. The staffs and administrators have a poor interpersonal interaction.

From the perspectives of social justice healthy environment with teaching and non-teaching staffs is essential and they would be involved in planning and decision-making that create honour to them.

\section{References}

Aslam, M. (2009). The relative effectiveness of government and private schools in Pakistan: are girls worse off? Education Economics, 17(3), 329-354.

Carney, S., \& Bista, M. B. (2009). Community schooling in Nepal: A genealogy of education reform since 1990. Comparative Education Review, 53(2), 189-211.

Case, J. M., \& Light, G. (2011). Emerging research methodologies in engineering education research. Journal of Engineering Education, 100(1), 186-210.

Furman, G. (2012). Social justice leadership as praxis: Developing capacities through preparation programs. Educational Administration Quarterly, 48(2), 191-229.

Furman, G., \& Gruenewald, D. A. (2004). Expanding the landscape of social justice: A critical ecological analysis. Educational Administration Quarterly, 40(1), 47-76. 
Gewirtz, S., \& Cribb, A. (2002). Plural conceptions of social justice: Implications for policy sociology. Journal of Education Policy, 17(5), 499-509.

Goldfarb, K. P., \& Grinberg, J. (2002). Leadership for social justice: Authentic participation in the case of a community center in Caracas, Venezuela. Journal of School Leadership, 12(2), 157-173.

Hansen, A., Byrne, Z., \& Kiersch, C. (2014). How interpersonal leadership relates to employee engagement. Journal of Managerial Psychology.

Hobbs, R. (2010). Digital and Media Literacy: A Plan of Action. A White Paper on the Digital and Media Literacy Recommendations of the Knight Commission on the Information Needs of Communities in a Democracy: ERIC.

Jean-Marie, G. (2008). Leadership for social justice: An agenda for 21 st century schools. Paper presented at the The Educational Forum.

Koirala, A. (2015). Debate on public and private schools in Nepal. International Journal of Social Sciences and Management, 2(1), 3-8.

Mathema, K. B. (2007). Crisis in education and future challenges for Nepal. European Bulletin of Himalayan Research, 31(46), 46-66.

Messick, D. (2006). Ethical judgment and moral leadership. Moral Leadership: The Theory and Practice of Power, Judgment and Policy. Hoboken: John Wiley \& Sons, Inc.

Minow, M. (1990). Making all the difference: Inclusion, exclusion, and American law: Cornell University Press.

Mullen, C. A. (2008). Theories and applications of social justice leadership. In: Taylor \& Francis.

Rawls, J. (1999). A theory of justice: Revised edition: Harvard university press.

Riehl, C. J. (2000). The principal's role in creating inclusive schools for diverse students: A review of normative, empirical, and critical literature on the practice of educational administration. Review of educational research, 70(1), 55-81.

Saldana, J. (2021). The coding manual for qualitative researchers: sage.

Salgur, S. A., \& Gursoy, A. (2015). Multicultral education and teacher's characteristics. Euromentor, 6(3).

Shah, V. (2018). Leadership for social justice through the lens of self-identified, racially and other-privileged leaders. Journal of Global Citizenship \& Equity Education, 6(1).

Stotzer, R. L. (2014). Law enforcement and criminal justice personnel interactions with transgender people in the United States: A literature review. Aggression and violent behavior, 19(3), 263-277.

Turhan, M. (2010). Social justice leadership: Implications for roles and responsibilities of school administrators. Procedia-Social and Behavioral Sciences, 9, 1357-1361. 
Wang, F. (2018). Social justice leadership_-Theory and practice: A case of Ontario. Educational Administration Quarterly, 54(3), 470-498.

Wells, K. (2011). Narrative inquiry: Oxford University Press, USA.

Wheelen, T. L., Hunger, J. D., Hoffman, A. N., \& Bamford, C. E. (2017). Strategic management and business policy (Vol. 55): pearson Boston, MA. 